\title{
Thoughts on neologisms and pleonasm in scientific discourse and tobacco control
}

\author{
Richard O'Connor,' Sarah J Durkin (1) ,' Joanna E Cohen (D), ${ }^{3}$ \\ Joaquin Barnoya (D) ,' Lisa Henriksen (D) , Sarah E Hill (D) ,' \\ Ruth E Malone (D) ${ }^{7}$
}

As public health reckons with the implications of language, word choice and their impacts, ${ }^{1-3}$ so too does Tobacco Control. Indeed, the editor-in-chief in 2010 pointed to the power of language in bounding discussions in the field. ${ }^{4}$ A common parlance or agreed on set of terms is important for moving science (and policy) forward-comparing like to like, allowing for replication, facilitating review and synthesis, and translating science into action.

Prior to 2000, the tobacco marketplace was, in retrospect, fairly simple. Cigarettes, chewing tobacco, moist snuff, dry snuff, cigars, pipes, waterpipes and bidis captured most of the marketplace. There were subtypes of products and regional variation to be sure, but the terms themselves were nearly universal. More recently, the tobacco marketplace has become increasingly diversified with the invention and marketing of new nicotine products. Terms have proliferated to try and capture this new complexity, while grouping conceptually or superficially similar products for ease of reference. This has occasioned a panoply of neologisms (newly coined words), retronyms (eg, 'tobacco cigarette' to distinguish from 'electronic cigarette') and portmanteau (new words formed from existing words), not to mention terms invented and used for a single paper (nonce words) or terms

\footnotetext{
${ }^{1}$ Department of Health Behavior, Roswell Park Cancer Institute, Buffalo, New York, USA

${ }^{2}$ Centre for Behavioural Research, Cancer Council Victoria, Melbourne, Victoria, Australia

${ }^{3}$ Institute for Global Tobacco Control, Johns Hopkins Bloomberg School of Public Health, Baltimore, Maryland, USA

${ }^{4}$ Departamento de Investigacion, Unidad de Cirugia Cardiovascular, Guatemala, Guatemala ${ }^{5}$ Stanford Prevention Research Center, Stanford University School of Medicine, Stanford, California, USA ${ }^{6}$ Global Health Policy Unit, University of Edinburgh, Edinburgh, UK

${ }^{7}$ Social and Behavioral Sciences, University of California, San Francisco, San Francisco, California, USA
}

Correspondence to Professor Richard O'Connor, Department of Health Behavior, Roswell Park Cancer Institute, Buffalo, NY 14203, USA;

richard.o'connor@roswellpark.org that are pleonastic (eg, novel and emerging products). Taking an opportunity to categorise the terms as a framework for discussion, table 1 below lists examples that we have seen in the last 5 years.

The diversity of this nomenclature is approaching absurdity. As terms proliferate, it becomes increasingly difficult to compare across papers as to whether researchers are studying the same type or class of products. Some adjectives carry more implications than others.

This editorial seeks to explore this phenomenon and examine the conditions under which these differentiated terms emerged and what they may imply. For the moment, at least, we take no position on the appropriateness of any particular term with respect to its use in the Journal, except for those already identified in our Author Guidelines. We do hope to: (1) encourage authors, reviewers, funders and readers to reconsider the use of these terms (and acronyms) and instead describe what is being studied more directly; (2) discourage authors from inventing a new term when acceptable alternatives exist and (3) encourage thinking about whether some terms should be retired.

The rise of e-cigarettes in the 2010s contributed greatly to the proliferation of terminology. Tobacco Control initially followed WHO's lead and preferred the use of electronic nicotine delivery systems (ENDS) for e-cigarettes. However, the term is less than beloved and many others have proliferated, some of which are potentially misleading. Take for example 'vaping products,' 'vaping devices' and 'to vape' as a verb. ENDS produce an aerosol (ie, particles and/or liquid suspended in a gas) rather than a vapour (ie, a substance in its gas phase below its critical temperature). E-cigarette users came to refer to themselves as vapers, in part to distinguish themselves from smokers, but in doing so reified the mistaken description of the product's output. Thus the use of 'vaping' terminology in research papers could be seen as the adoption by scientists of consumer and industry parlance in substitution for more accurate descriptors. This is not hair-splitting, as some evidence suggests 'vapour' is perceived as less harmful than 'aerosol. ${ }^{5}$ Yet, the term has become entrenched in common usage, and even extended to describe a whole retail sector (eg, vape shops).

Another example is the commonly used 'e-liquid,' a term used for the nicotine solution loaded into ENDS for inhalation. This is a portmanteau of electronic (cigarette) liquid, yet there is nothing electronic about the liquid itself. Yes, e-liquid is shorthand, but the 'e-' does a lot of work, implying something high-tech rather than a chemical solution of propylene glycol, glycerine, additives and nicotine. Terminology around ENDS is also complicated by differences in regulation. For example, the United States treats ENDS as tobacco products, whereas in the European Union and other jurisdictions, they are nicotine products. 6 So, depending on one's country, 'tobacco products' (possibly the broadest term) is either inclusive or exclusive of ENDS.

Claimed reductions in harm or risk. PREP (potentially reduced exposure products) emerged from a 2001 report of the US Institute of Medicine, ${ }^{7}$ and was quickly adopted by the tobacco industry for products marketed or positioned as less harmful than cigarettes, along with the broader co-option of the concept of 'harm reduction' by industry. ${ }^{8} 9$ PREP was supplanted by MRTP (modified risk tobacco product) ${ }^{10}$ after the US Food and Drug Administration (FDA) gained regulatory authority over tobacco products in 2009. The terminology refers to a specific regulatory review process by which products could receive FDA authorisation to claim reduced exposure or risk. Philip Morris International (PMI) and Japan Tobacco International (JTI) have used 'reduced risk products' as a blanket term for products they intend to position as reduced harm. We would argue that MRTP, in particular, should be reserved specifically for products that-in the US market-have applied for and/or been granted the marketing order by FDA.

Emergence, Novelty and Progress. 'Emerging' and 'novel' can be awkward terms, given they are time dependentlogically, a product can only be emerging or novel early in its life, in a particular market. Yet, some researchers continue to describe ENDS as emerging or novel, despite these products' presence for more than a decade and-in some (particularly youth) markets-their dominance over cigarettes in terms of sales. The term 'alternative' is similarly problematic. Denoting 
Table 1 Examples of descriptive terms for nicotine products, organised by their implications

\begin{tabular}{|c|c|c|c|}
\hline Implies lower risk & Implies novelty or innovation & Overly broad & Arguably neutral \\
\hline Heat-not-burn products & Alternative tobacco products (ATP) & Conventional tobacco products & Commercial tobacco \\
\hline Harm reduction products & Alternative and emerging tobacco products (ATP) & Nicotine products & Combustible/ed tobacco \\
\hline Modified risk tobacco product (MRTP & Modern oral & Non-cigarette tobacco products & Electronic cigarettes (e-cigarettes) \\
\hline Nicotine vaping products (NVP) & New and emerging nicotine products & Other tobacco products (OTP) & Electronic nicotine delivery devices (ENDS) \\
\hline $\begin{array}{l}\text { Potentially reduced exposure products } \\
\text { (PREP) }\end{array}$ & New and emerging tobacco delivery products & $\begin{array}{l}\text { Tobacco and other nicotine products } \\
\text { (ToNic) }\end{array}$ & Electronic nicotine delivery systems (ENDS) \\
\hline Reduced-risk products (RRP) & $\begin{array}{l}\text { Newer and novel nicotine and tobacco products } \\
\text { (NNNTPs) }\end{array}$ & Tobacco products & Electronic nicotine devices (END) \\
\hline Smokeless tobacco & Next generation products (NGP) & Traditional tobacco & Electronic nicotine product \\
\hline \multirow[t]{8}{*}{ Vaporised nicotine products (VNP) } & Novel and emerging products & & $\begin{array}{l}\text { Electronic non-nicotine delivery systems } \\
\text { (ENNDS) }\end{array}$ \\
\hline & Novel tobacco and nicotine products & & Electronic smoking devices (ESD) \\
\hline & 'Nth generation' & & Heated tobacco products \\
\hline & & & Non-combustible nicotine products (NCNP) \\
\hline & & & Non-combustible/ed tobacco \\
\hline & & & Oral tobacco \\
\hline & & & Oral nicotine products \\
\hline & & & Tobacco Heating Products \\
\hline
\end{tabular}

a choice between two or more mutually exclusive options, 'alternative tobacco products' is a misnomer where dual and polytobacco use is the norm. The term also connotes counter-cultural appeal or deviation from norms. Another common rhetorical device is to categorise ENDS products into three or more 'generations', with later generations denoting either (1) greater device complexity (a concept with diverse interpretations) or (2) more recent introduction to the marketplace (cf. mobile phones). An extension of this rhetorical tactic is PMI and Imperial's use of 'next generation products' as an umbrella for their electronic cigarette, heated tobacco products and oral nicotine products. These framings imply substantive improvements, advancement and progress, which are generally viewed as universal goods. It also allows manufacturers to frame themselves as moving away from older products (cigarettes) associated with disease and death.

Language can help to shape our thinking, including setting boundaries for discourse and policy options. ${ }^{411}$ Language also evolves over time, and there is little sense standing athwart it. However, it is helpful to strive toward greater accuracy and consistency, and also to reject terms that perpetuate tobacco industry interests. In a practical sense, this plethora of names makes writing and enforcing policies around these products even harder. The body of evidence that informs strong smoke-free air laws in many countries characterises the content and health harms of secondhand smoke and more recently, thirdhand smoke, rather than using the term 'environmental tobacco smoke,' an industry-favoured construction that suggested smoke was one among many pollutants that could be addressed by better air filtration rather than smoke-free policies. As editors, we encourage authors, readers and those who put science to work in policy to take the extra seconds needed to consider carefully their choice of terms and what they might unwittingly imply about the product under study. Clearer discourse and clearer thinking can lead to better science, more effective policy and, ultimately, the improvements to public health that we all seek.

Correction notice This paper has been updated since first published to amend details of Reference 6 .

Twitter Ruth E Malone @MaloneRuth

Funding The authors have not declared a specific grant for this research from any funding agency in the public, commercial or not-for-profit sectors.

Competing interests None declared.

Patient consent for publication Not required.

Provenance and peer review Not commissioned; internally peer reviewed.

(c) Author(s) (or their employer(s)) 2021. No commercial re-use. See rights and permissions. Published by BMJ.

$$
\text { Check for updates }
$$

To cite O'Connor R, Durkin SJ, Cohen JE, et al. Tob Control 2021:30:359-360.

Published Online First 27 June 2021

Tob Control 2021;30:359-360.

doi:10.1136/tobaccocontrol-2021-056795

\section{ORCID iDs}

Sarah J Durkin http://orcid.org/0000-0002-2795-6454
Joanna E Cohen http://orcid.org/0000-0002-38693637

Joaquin Barnoya http://orcid.org/0000-0002-1731$479 X$

Lisa Henriksen http://orcid.org/0000-0002-9288-3562 Sarah E Hill http://orcid.org/0000-0003-3555-433X

Ruth E Malone http://orcid.org/0000-0002-3324-2183

\section{REFERENCES}

1 Krisberg K, Verga D. What's in a word? How language affects public health: Research shows word choices can influence well-being, treatment. The Nation's Health. Washington, DC: American Public Health Association, 2018: 1-10. https://www. thenationshealth.org/content/48/2/1.1

2 Verga D. How we talk about public health and why it matters. path, 2020. https://www. path.org/articles/ how-we-talk-about-public-health-and-why-it-matters/

3 Choice words and word choices 2016, 2021. Available: https://www.nih.gov/about-nih/what-we-do/sciencehealth-public-trust/perspectives/choice-words-wordchoices [Accessed 17 May 2021].

4 Malone RE. Word wars and tobacco control: saying what needs saying that we don't yet know how to say, or saying it better. Tob Control 2010;19:261-2.

5 Rossheim ME, Zhao X, Soule EK, et al. Aerosol, vapor, or chemicals? college student perceptions of harm from electronic cigarettes and support for a tobaccofree campus policy. J Am Coll Health 2020:1-7.

6 Munafò M. Are e-cigarettes tobacco products? Nicotine Tob Res 2019;21:267.

7 Stratton K, Shetty P, Wallace R, et al. Clearing the smoke: the science base for tobacco harm reduction-executive summary. Tob Control 2001;10:189-95.

8 Dewhirst T. Co-optation of harm reduction by big tobacco. Tob Control 2020. doi:10.1136/ tobaccocontrol-2020-056059. [Epub ahead of print: 12 Aug 2020].

9 Peeters S, Gilmore AB. Understanding the emergence of the tobacco industry's use of the term tobacco harm reduction in order to inform public health policy. Tob Control 2015;24:182-9.

10 Administration FaD. Modified risk tobacco products 2021. Available: https://www.fda.gov/tobaccoproducts/advertising-and-promotion/modified-risktobacco-products

11 Zlatev J, Blomberg J. Language may indeed influence thought. Front Psychol 2015;6:1631. 


\section{Correction: Thoughts on neologisms and pleonasm in scientific discourse and tobacco control}

O'Connor R, Durkin SJ, Cohen JE, et al. Thoughts on neologisms and pleonasm in scientific discourse and tobacco control. Tob Control 2021;30:359-360. doi:10.1136/ tobaccocontrol-2021-056795

This paper has been updated since first published to amend details of Reference 6 .

(C) Author(s) (or their employer(s)) 2022. No commercial re-use. See rights and permissions. Published by BMJ.

Tob Control 2022;31:e1. doi:10.1136/tobaccocontrol-2021-056795corr1

(D) Check for updates 